\title{
Western European
}

National Cancer Institute

\section{Source}

National Cancer Institute. Western European. NCI Thesaurus. Code C77817.

Denotes a person having origins in any of the countries of Western Europe such as Spain, Portugal, or France. 